\title{
STUDIES
}

Article received on March $8^{\text {th }} 2020$

Article accepted on June $5^{\text {th }} 2020$

Original scientific paper

UDC 78.01

78.038 .6

\author{
Jiří Kubíček* \\ Palacký University, Olomouc \\ Faculty of Arts \\ Department of Musicology
}

\section{FROM KERMAN TO MERZBOW: NOTES ON THE METAMORPHOSES OF MUSIC ANALYSIS AT THE TURN OF THE MILLENNIUM}

\begin{abstract}
This paper aims to delineate changes in the approach to music analysis over the last decades of the nineteenth century and to examine different possibilities in analysing works which have a characteristic that virtually excludes the use of traditional methods. The starting point is Joseph Kerman's criticism of music analysis, formulated in the 1980s, which - together with successive discussions - reflects a tendency towards abandoning the excessively academic and formalizing approach to analysis, moving from an attempt at an objective analysis of a work towards an interpretation that also focuses on the listener. Since the mid-twentieth century, elec-
\end{abstract}

* The author’s contact details: kubicek.jiri@gmail.com 
troacoustic music has been one of the areas where the use of traditional analysis was inconvenient. Since electroacoustic music began to lose its exclusive, academic character in the 1990s in relation with the development of computer technologies, the question of its interpretation and finding suitable listener strategies has kept coming to the fore. This paper shows the possibilities of approach to this music in relation to its specificities. The last part of the paper focuses on a specific example from one fringe genre: noise music, specifically the subgenre japanoise. In its peak period in the 1990s, this sound production was probably the furthest away from what is usually associated with the term music. Based on an analysis of a selected composition, the inadequacy of the traditional approach and certain alternatives to grasping such music will be demonstrated. The very end of the paper features some current results which relate to, or result from, the study's conclusions.

Keywords: analysis, electroacoustic music, japanoise, Merzbow, noise music, organicism

\section{"How We Got into Analysis...}

....and How to Get Out". This how Joseph Kerman titled a study in which he attacked the contemporary approach to music analysis. He states that analysis strives to be a science, but in reality, it is more of an ideology, "a fairly coherent set of ideas brought together [...] in the service of some strongly held communal belief". ${ }^{2}$ By that, he meant the belief in the concept of organic unity, as manifested predominantly in instrumental music of the great German tradition from Bach to Brahms. Kerman shows how analysis gradually became a means to uncover this hidden unity as a fundamental force believed to instil value into the masterworks. There is a clear connection between ideology, analysis, organicism, and aesthetic value: "From the standpoint of the ruling ideology, analysis exists for the purpose of demonstrating organicism, and organicism exists for the purpose of validating a certain body of works of art". 3 Organicism thus became an implicit criterion of aesthetic value of music in general. This is pointed out by Kerman towards the end of his study: "What is important is to find ways of dealing responsibly with other kinds of aesthetic value in music besides organicism".

1 Joseph Kerman, "How We Got into Analysis, and How to Get Out", Critical Inquiry, $7(2), 1980,311-331$.

2 Ibid., 314.

3 Ibid., 315.

4 Ibid., 331. 
Kerman was neither the first nor the only scholar who brought attention to the necessity of changing the approach to music analysis, yet his conclusions are highly debatable. It is no coincidence that Nicholas Cook has labelled this a "cruel caricature of analysis". ${ }^{5}$ Nevertheless, the concept of organic unity, one of the targets of Kerman's attack, had still been an apt topic twenty-five years later, as documented by a debate from $2004 .{ }^{6} \mathrm{In}$ it, J. D. Kramer draws our attention to the opposite opinion:

Disunity needs to be appreciated not only as the absence of unity, but also as a musical experience in and of itself. [...] Analyses that seek to understand the means and purposes of musical disunity [...] do indeed offer listening strategies to deal meaningfully with the experiences of musical conflicts and inconsistencies. $^{7}$

The shift from the conception of music analysis as a science, from positivism and formalism, was also among the motives behind discussions at the turn of the century. Analysis as a science was meant to produce unequivocal results: proper analysis (made using proper techniques) was meant to yield the proper understanding of a given work. Nicholas Cook shows how the results of an analysis, endowed with the appearance of scientific liability, became a criterion for assessing aesthetic values. One of the problematic effects is the fact called aesthetic determinism by Cook; it consists of an effort to derive aesthetic properties directly from the music structure, stored in a formalized musical notation, resulting in "the 'deletion of the listener' as a free agent; he is replaced by a theory which correlates the material properties of the music with the appropriate aesthetic response [...]". ${ }^{8}$ However, current discussions against positivism (which, according to Kofi Agawu, is propagated by confidence that in the modern economic system, even academic activities should always produce unequivocal and quantifiable results) brought about another,

\footnotetext{
5 Nicholas Cook and Mark Everist, Rethinking Music, Oxford, Oxford University Press, 2010, xi.

6 The debate was sparked by R. P. Morgan's article regarding the conception on the unity in the particular analyses of five authors, to which all of them reacted in the subsequent issue. See Robert P. Morgan, "The Concept of Unity and Musical Analysis", Music Analysis, 22(1/2), 2003, 7-50.

7 Jonathan D. Kramer, "The Concept of Disunity and Musical Analysis", Music Analysis, 23(2/3), 2004, 362.

8 Nicholas Cook, A Guide to Musical Analysis, Oxford - New York, Oxford University Press, 1987, 223.
} 
more playful notion: there is no 'proper' analysis ${ }^{9}$ - each analysis is always a new interpretation of a work, a repeated reinvention of the wheel. ${ }^{10}$

\section{On the Analysis of Electroacoustic Music}

The need for creative invention as called for by K. Agawu increases in the analysis of electroacoustic music (hereinafter, EA music). ${ }^{11}$ Properties essential to traditional music and, consequently, to its analysis (in particular, harmonic-tonal and melodic-thematic relations which, collectively, formed a basis for established, hierarchically created forms) are either absent in EA music, or lose their priority. Instead they are replaced by new key attributes such as the timbral and spectral properties of sound objects ${ }^{12}$ including their changes in time, horizontal and vertical mutual relations of sound objects (as well as silence), relations between the sound objects and the spectral, acoustic and physical space, etc. The unmatched extent of the histories of traditional music and EA music are equally important, including the history of the formulation of their theories and aesthetics based on existing analyses. Moreover, the relatively short history of EA music takes place entirely at a time where there are no generally binding compositional and music-theory systems, standards, and rules, which would serve as a basis for more or less universally applicable analytical methods.

9 On the other hand, Umberto Eco shows that "[...] if it is very difficult to decide whether a given interpretation is a good one, it is, however, always possible to decide whether it is a bad one [...]" (Umberto Eco, The Limits of Interpretation, Bloomington, Indiana University Press, 1994, 42).

10 Kofi Agawu, "How We Got Out of Analysis, and How to Get Back In Again”, Music Analysis, 23(2/3), 2004, 275.

11 In accordance with The New Grove Dictionary of Music and Musicians, this term will be used for "music in which electronic technology, now primarily computer-based, is used to access, generate, explore and configure sound materials [...]" and which altogether or to a considerable extent lacks the attributes of traditional music (for this term, see ibid., we will adhere to it in this text, too). See Simon Emmerson and Denis Smalley, "Electro-acoustic music", in: Grove Music Online [online]. [cit. 2018-09-11], https://doi. org/10.1093/gmo/9781561592630.article.08695.

12 The term sound object (in French: Objet sonore, also translated as sonic object) was introduced in the EA music context by Pierre Schaeffer. See Pierre Schaeffer, Treatise on musical objects: essays across disciplines, transl. Ch. North and J. Dack, Oakland, University of California Press, 2017, 69, 210. 
Umberto Eco postulates three possible approaches to the interpretation of text: ${ }^{13}$ from the viewpoint of the author (intentio auctoris), reader (intentio lectoris), and the work itself (intentio operis). ${ }^{14}$ While the traditional, mainly formalistic music analysis predominantly relied on the latter approach, an increased emphasis has been placed on the listener's experience in recent decades, i.e. Eco's intentio lectoris is increasingly involved. Composer James Andean also draws on the listener's experience, trying to define several narrative modes, through which the listener can perceive EA music and modify his/her experience of a certain work. Andean found ten different modes: material, formal, structural, mimetic, embodied, parametric, spatial, studio, textual, extramusical. ${ }^{15}$ Some of them only appear in the context of EA music; this primarily concerns the spatial narrative (in contrast to the conventional understanding, it reverses the space-sound relation - space is usually only perceived as a setting for the articulation of sound, but here, on the other hand, sound is only perceived as a means to articulate the space) and the studio narrative (primarily examining the technical details of sound processing; is common among listeners who themselves compose $E A$ music). Others, by contrast, can be viewed as universal, but their application to EA music may be different than in the case of traditional music. This is the case of the formal narrative (which consists in the search of formal structure of a higher hierarchic level, e.g. ternary form - ABA) and, especially, of the structural narrative (which monitors the syntax of a language through which the particular musical work is expressed). EA music obviously uses different means than traditional music to express both the formal and syntactic aspects. The situation is especially complicated in the structural narrative, where in many ways, parallel development resulted - as opposed to, for instance, tonal music and its essentially unambiguous syntactic rules - in "not so much in a loss of syntax, but in its multiplication". ${ }^{16}$ There are also genres where it is not possible to speak of formal or structural narrative at all. This may be caused, for instance, by

13 The term text is referred to in a broad sense, in terms of semiotics, and it can therefore denote a musical composition.

14 Umberto Eco, op. cit., 50.

15 For a more detailed explanation of the individual modes, see James Andean, "Narrative Modes in Acousmatic Music", Organised Sound, 21(3), 2016, 192-203. Even though all the narrative modes are based on the intentio lectoris, the content of some of them rather falls within the intentio operis (formal, structural narrative) or even the intentio auctoris (extramusical narrative).

16 James Andean, op. cit., 195. 
an extreme fragmentation of a music stream, where the individual elements bear no relation to each other and music becomes unpredictable in principle; ${ }^{17}$ this weakens the link between the past, present, and future course of the composition, with the increasing significance of the 'now'. So, the method of structuring time in music may be one of the points which lay out the boundaries between music, to which some analogies from the analysis of traditional music can be applied, and music for which wholly new methods of analytical thinking must be applied.

Given what has so far been stated in this chapter it is no surprise that no analytical methods exist for EA music which would be widespread and important enough to compare with, for example, Schenker's analysis. ${ }^{18} \mathrm{Nev}$ ertheless, attempts to create suitable terminology and graphic representations for the study of EA music have been under way practically since its beginning in the mid-20th century.

One of the first steps was taken by Pierre Schaeffer, the pioneer of acousmatic music and author of the monumental volume Traité des Objets Musicaux Essai Interdisciplines, ${ }^{19}$ by introducing the term écoute reduite (reductive listening). In doing so, sound should indeed be perceived as a mere sound, and the interest in its origin, significance, and place within the structure of a composition, etc., should be placed between 'brackets'. This allowed him to describe and classify sound objects purely based on their sonic qualities, releasing them from any other relationships. At the time, Schaeffer's typology and morphology was an original idea as a taxonomic system to classify and describe sound objects, and has maintained its influence in the decades since.

17 The beginnings of this approach date back to K. Stockhausen in relation to the concept of Momentform. Stockhausen speaks of forms, "[...] in denen nichts rastlos ein jedes Jetzt als bloßes Resultat des Voraufgegangenen und als Auftakt zu Kommendem, auf das man hofft, angesehn wird, sondern als ein Persönliches, Selbständiges, Zentriertes, das für sich bestehn kann [...]" (Karlheinz Stockhausen, "Momentform: Neue Beziehungen zwischen Aufführungsdauer, Werkdauer und Moment”, in: Dieter Schnebel (Ed.), Texte zur Musik, vol. 1, Cologne: DuMont Schauberg, 1963, 199).

18 Gatt notes in this context: "This lack of a general consensus might be viewed as a negative attribute of electroacoustic music, when in fact it is a positive one. Although it does not provide solid grounding for a singular methodology it does allow for many different perspectives on a particular work." (Michael E. Gatt, Tools for Understanding Electroacoustic Music. Thesis submitted for the degree of Doctor of Philosophy, Leicester, De Montfort University, 2014, 13).

19 Pierre Schaeffer, op. cit. For French original, see Pierre Schaeffer, Traité des Objets Musicaux Essai Interdisciplines, Paris, Éditions du Seuil, 1966. 
Spectromorphology is a system developed by Denis Smalley "as tools for describing and analysing listening experience". ${ }^{20}$ Smalley warns against overrating the pure reductive listening, while introducing the term source-bonding, which is based on 'the natural tendency to relate sounds to supposed sources and causes.. ${ }^{21}$ On the other hand, the system builds on Schaeffer's typomorphology and makes a very detailed classification of all conceivable properties of sound objects: their internal movements and structure, mutual relationships as well as distribution, and their density and movement in the spectral and physical space. Regarding analysis, such a detailed description is valuable partly by providing a very extensive set of attributes to choose from to characterize any sound object, partly by establishing the necessary terminology. Yet, it has no ambition to be an analytical method in terms of a general 'guideline' for analysing EA music.

The analysis of EA music is further complicated by the fact that traditional musical notation is seldom used. Graphic representations of EA music are most commonly created by spectrograms. There are programmes which not only to visualize, but also manipulate a track's sound content. A frequently used tool is the Sonic Visualiser, a free, open-source application developed at the Queen Mary University of London. The spectrogram itself is widely extendable with add-on analytical functions thanks to third-party plugins. Spectrogram-based sound manipulation (duplication, moving and other alterations of the selected sound clippings) can be made, for instance, by Steinberg's SpectraLayers commercial software. Michael Clarke and his colleagues are developing a very interesting tool intended specifically to analyse $E A$ music. ${ }^{22}$ It is based on Nattiez's semiotic analysis principle, where individual elements are isolated from the track in the paradigmatic stage and arranged in a paradigmatic chart, after which, during the syntagmatic stage, their distribution within the track, frequency, variations, etc., are analysed. While motivic particles usually play the role of these elements in traditional music, timbrally- and spectrally-defined sound objects appertain to EA music. A graphic interface similar to a spectrogram assists in isolating such sound objects within a track, interconnecting them with the paradigmatic chart, and

20 Denis Smalley, "Spectromorphology: Explaining sound-shapes”, Organised Sound, 2(2), 1997, 107.

21 Ibid., 110.

22 Michael Clarke, "Analysing Electroacoustic Music: An Interactive Aural Approach", Music Analysis, 31(3), 2012, 347-380. 
then playing them in isolation from the surrounding horizontal and vertical context, reorganizing them within the track, changing their spectral properties, and so on. ${ }^{23}$

\section{On the Analysis of Noise Music}

The analysing of noise music ${ }^{24}$ is a terra incognita, as reflected in the words of prominent theorist of EA music Leigh Landy: "Although I have had students attempt to analyse noise music, I am not aware of published analyses thus far. I find this unfortunate, for we seem to be postponing gaining knowledge about music that is currently innovative". ${ }^{25}$ I happened to find an analysis of a track by Merzbow (Amelides 212); ${ }^{26}$ it is, however, very superficial, and the most interesting part of the article are the questions asked in the conclusion, casting doubts on the purpose of analysing something like noise music. Similar questions are posed later in this study.

The basic principle of noise music production is to allow sound from any source (a musical instrument, any other object, human voice, or a device that produces sound or noise) to pass through a feedback loop, which is then amplified far beyond the distortion threshold, modulated, and filtered. Performers employed predominantly analogue devices (including effects pedals) for to this end even in the 1990s, as they were able to use the controllers to dynamically change the values of various sound parameters in real time. The result is literally a flood of sound (or rather noise distorted to varying degrees), which vertically fills a considerable part of the frequency spectrum in a very comprehensive way, and horizontally undergoes permanent, mostly irregular and unpredictable changes in various frequency bands. In addition,

\footnotetext{
23 A presentation with SW use examples is available on the University of Huddersfield website. See TaCEM. University of Huddersfield, 2002 [online], [cit. 2018-09-11], https:// research.hud.ac.uk/institutes-centres/tacem/ .

24 In this study, the term noise music will denote specific music the barycentre of which lies in the 1990s, primarily in Japan. It is sometimes called japanoise or harsh noise and is associated with projects and performers like Merzbow, Incapacitants, CCCC, and Hiroshi Hasegawa. This narrow definition was chosen because the extreme nature of this type of music is most obvious in it, which suits the research aims.

25 Leigh Landy, Understanding the art of sound organization, Cambridge, Mass., MIT Press, 2007, 129

26 Panos Amelides, Meattrapezoid Analysis, 2012 [online], [cit. 2018-09-11], http://www. orema.dmu.ac.uk/analyses/panos-amelides-meattrapezoid-analysis.
} 
it seems as if the sound was granular in nature, on a micro-level. Exceptionally, a relatively isolated sound object ${ }^{27}$ gains prominence - these objects are mostly drowned out in the surrounding noise, but they can be separated by listening (and in most cases also identified visually on the spectrogram). Yet the original sources of the sounds are rarely decipherable due to the extreme distortion and further modulation.

There are generally two types of sound objects within this kind of music production:

- Sounds resulting from the considerable amplification of noise in a narrow frequency band - these sounds retain their noise character, they seem 'cut out' from the noise;

- Sounds for which another origin is evident (although this usually cannot be specified), as their sound character is different.

However, there are just a handful of distinctive sound objects, as the bulk of the sound matter consists of varying noise. It is therefore necessary to propose criteria to describe and classify sound activity based almost exclusively on noise. From the vertical, static viewpoint, there are only different levels of intensity in various frequency bands, and these bands can have various widths. A higher diversity of potential criteria can be found on the horizontal axis, describing the dynamic character of sound. It is possible to propose the following subdivision:

A) noise proceeds relatively unchanged for some time (seconds or dozens of seconds), not taking minor oscillations into account, sound 'speckling', granulation - constant sound activity on the micro-level (in fractions of seconds);

B) long-term considerable reductions or increases of intensity in one or several layers;

C) one or several layers sounding intermittently, while the individual signals last for several seconds, or even fractions of seconds; the interruptions are not regular;

D) regular oscillations in one or several layers.

27 From the spectral viewpoint, such a sound object is distinguished by a strongly represented single or several relatively narrow frequency bands, usually with continuous development over time; it is relatively sharply defined horizontally (time) as well as vertically (frequency). From the viewpoint of listening experience, one can feel as though they come from a single source different from the surrounding noise. 


\section{Examples of noise music analyses}

Masami Akita, best known under the moniker of his long-standing project, Merzbow, is the most prominent figure in this genre. He participated in the creation, development, and definition of noise music to a significant degree. His discography is abundant, containing hundreds of works, and I have chosen the composition Wing Over from the early $1990 \mathrm{~s}^{28}$ - partly by random choice, and partly for being typical of the characteristics of this kind of music, as described above. The track predominantly consists of aggressively distorted noise, constantly varying on both the micro- and macro-level. It lacks regularity, repetition; one of the fundamental characteristics is the unpredictability of the development of the music in any moment of the track. From the acoustic point of view, the sound energy is arranged over the whole width of the sonic spectrum. The spectral centroid ${ }^{29}$ lies, on an average, in the range between 3.5 and $6 \mathrm{kHz}$, being the highest of all the four compositions compared (the lowest is Mozart's Symphony No. 29 in A Major - roughly 1-2.5 $\mathrm{kHz}) .^{30}$ An increased presence of higher frequencies results in an aggressive sound, and unease and feelings of discomfort when listening, at least for an untrained listener. ${ }^{31}$ With respect to the noise character, it is no surprise that there is a high rate of so-called spectral flatness - the sound energy is arranged across the spectrum independently of periodical frequencies of harmonic tones. This, again, stands out especially when comparing the spectrograms of the track analysed and that of Mozart's Symphony No. 29.

The analysis was based on a basic segmentation of the work into five sections, each 3-6 minutes long; I chose this measurement because, on one hand, it is possible to work in detail with sections of this length, and, on the

28 Merzbow, Artificial Invagination: Wing Over, Vanilla, 1991, in: Youtube [online]. [cit. 2018-09-11], https://www.youtube.com/watch?v=MRDphofU5qY\&t=876s .

29 The spectral centroid specifies the central frequency where lies the weighted average of all currently sounding frequency bands; each of them contributes to the mean in proportion to the signal strength it contains. The higher the value, the higher number of higher frequencies the total signal contains in the given moment and the higher its brightness is. For a more detailed explanation, see Zachary T. Wallmark, Appraising Timbre: Embodiment and Affect at the Threshold of Music and Noise. A dissertation submitted in partial satisfaction of the requirements for the degree Doctor of Philosophy in Musicology, Los Angeles, University of California, 2014, 57.

30 See attached images.

31 Wallmark explains the evolutionary significance of sensitivity to higher frequencies (Zachary T. Wallmark, op. cit., 58-60). 
other, the method of frequency spectrum filling can be roughly stated with such lengths (in both the horizontal and vertical direction), in accordance with the previous classification, which predominates in the given sections. It must once again be emphasized that this (or basically any other) specific segmentation is solely my selection and does not follow any fundamental structural divides within the track.

Segment 1 (0:00-5:20)

The beginning of this section (roughly until 1:25) is a very complex, varying section, with at least seven distinct sound objects and intensive movement over various frequency bands. The rate of change as well as the occurrence of identifiable sound objects is markedly lower in the rest of this section; the movement is based, in particular, on types A and B - these are actually dominating types of movements, but all types of sound activities occur there to a certain extent (see, for instance, rhythmic pulses in the band around $2-3 \mathrm{kHz}$ at 3:50-4:00).

\section{Segment 2 (5:20-8:47)}

This section is based again on an increased density of sound objects (even extensive ones), but in addition, type B movement dominates again with a relatively high rate of change; with the exception of a relatively extensive soundscape at 6:47-7:10, with constant chirps around $1.3 \mathrm{kHz}$ contrasting with the continuous sound mass in the range below $300 \mathrm{~Hz}$.

Segment 3 (8:47-11:37)

This section almost exclusively comprises extensive soundscapes (several dozen seconds long), frequency bands of various width inside the soundscapes feature varying, yet steadily maintained intensity - but, as mentioned above, constant sound activities take place on the micro-level within these stable soundscapes; the only distinctive sound object which is not composed of mere noise is a sort of 'blow-out' to a short pause at 11:13.

Segment 4 (11:37-14:05)

Type $\mathrm{C}$ dominates the first part; sound activities become more varied from 13:15, which will be analysed at greater length later in this study.

Segment 5 (14:05-20:54)

The dominant type of sound movement in this section is type A, gradating towards the end (roughly from 17:20) in a very dynamic flow with frequent changes and abruptions in various bands and with several distinct sound objects. 
This example continues with a detailed analysis of the concluding part of segments 4 . This section was chosen because it presented relatively the highest diversity and variability in sound. It is possible to identify three individual sound objects clearly standing out from the noise background which become the forefront, a figure (please note that my aim is to metaphorically describe the sounds, rather than speculate about its actual origin):

- 13:19-13:21 (hereinafter 'S1') a vibrating sound resembling an ocarina, without overtones, with a fast tremolo, occupying the band around 500 $\mathrm{Hz}$ in the sonic spectrum;

-13:22-13:28 ('S2') a metallic sound comprised of two spectral components:

- A sharp sound with a barycentre around $4 \mathrm{kHz}$ and higher;

A clearer sound with clean harmonics from the basic tone at approx. $230 \mathrm{~Hz}$ (which, in effect, is missing - in reality, the third harmonic is notably present, roughly $700 \mathrm{~Hz}$ ) to somewhere beyond 4 $\mathrm{kHz}$; it is, then, approximately $\mathrm{Bb}$;

- The second component always follows as a reverberation of the first one, while both components are arguably parts of a single sound from one source; the aggregate sounds roughly as very aggressive blows or the rubbing of metallic objects with the subsequent fading of their vibrations;

- 13:55-14:01 ('S3') a sound suggestive of something like a car horn or a buzzing giant fly, with a time characteristic that forms a descending glissando (during the first three seconds, the sound descends by roughly a major second interval); the sonic spectrum is once again filled with a harmonic line, the basic tone of which (once the glissando ends) is at approx. $170 \mathrm{~Hz}$, i.e. approximately the tone $\mathrm{F}$.

Detailed analysis of the concluding part of segments 4 (13:15-14:03)

\section{3:15-13:18}

A section lacking horizontal structuring. Vertically, the space is comprehensively filled with noise on all frequencies. Lower components (approx. 400 $\mathrm{Hz}$ and below) are mainly represented in the right channel. The band around $1.6 \mathrm{kHz}$ is somewhat amplified; there is also a sharp, metallic treble roughly at $4-5 \mathrm{kHz}$ - this sound is very similar to the first component of sound S2.

\section{$13: 18-13: 22$}

The overall noise intensity drops, the only band that remains amplified throughout is the band around $1.6 \mathrm{kHz}$. The amplified noise in the upper 
band fades out for roughly 1.5 seconds, and once turned down, S1 can be heard.

\section{$13: 22-13: 28$}

This part is based on three instances of sound described above as S2. It is not a triple use of the same sample; the sound is apparently created live, as it is similar in nature each time, but with differing waveform. Roughly towards the half of the section, the lower part of the spectrum (under $200 \mathrm{~Hz}$ ) is amplified.

\section{$13: 28-13: 33$}

Once again, some metallic sound which fills the whole spectrum relatively evenly. It is uninterrupted for two seconds, with irregular rhythmizations roughly each occurring for a half-second.

\section{3:33-13:37}

The sound continues with the rhythmic pulsing passing to the alternately amplified and attenuated bass component of the noise.

\section{3:37-13:45}

The frequency spectrum is comprehensively filled again, with heavily amplified low frequencies. Constant sound fluctuations take place in all parts of the spectrum, and a hint of a regular rhythmic pulse can be heard toward the end.

\section{3:45-13:55}

This is a very complex section internally, which could further be fragmented and examined in small parts.

\section{3:55-14:03}

The single dominating element of this section is the sound S3, which, however, appears as if it were crumbling to other parts of the spectrum. The last three seconds are relatively empty as regards sound.

We could continue in this manner to smaller and smaller time units, to levels shorter than a second, and could still encounter the same amount of unpredictability. It can even be argued that on the micro-level - if the listener properly focuses his or her attention - the sound activity is variegated the most. Another step could be to detail the measurement of energy in various layers of the spectrum in suitably selected segments of the track, followed by a statistical comparison in the hope to find some sort of order in all of the unpredictability, despite the fact that the performer's intention, in all likelihood, was not heading this way. It is, however, clear that such an approach would 
oppose the spirit of noise music and the purpose would be debatable. For that matter, a similar question can also be asked in relation to this analysis. One partial reply could be that such an analytical description can efficiently support more adequate listening, especially in connection with a graphic depiction in the form of a spectrogram. Thanks to the detailed analysis, a listener (and an analyst even more so) is able to 'settle' the composition with ease. The main potential of the analysis will then consist of its ability to facilitate grasping noise music as music. But is it desirable to try to 'settle' noise music, to attempt to grasp it as music? And, if yes, as what kind of music? What is meant by a 'kind of music'?

\section{A path to another approach to noise music}

Let us borrow some thoughts of Greg Hainge from his book on the ontology of noise ${ }^{32}$ to terminologically and factually open the way to other potentialities of understanding noise music. In the chapters about musique concrète as well as about Merzbow, Hainge contrasts the terms music and musicality; the first is defined ontologically, ${ }^{33}$ the second is delineated by a certain set of attributes and sonic qualities music can acquire. The extent and form of this 'allowed' set is always historically, culturally, or otherwise subjectively conditioned. Unfortunately, the term music in the general sense is used in a meaning attached to the term musicality - and the result is that sonic expressions that do not fit into the 'allowed' set are expelled from music and become noise. To avoid further potential confusion, Hainge uses a similar terminological manoeuvre, confronting the ontological and common sense definition of the term noise. Whereas the boundary between the signal and the noise, or, say, between music and noise, is arbitrary in common sense, again depending on specific historical, cultural, and various subjective conditions, noise in the ontological sense is an unavoidable part of every expression. This is also true of all sonic expressions:

32 Greg Hainge, Noise matters: towards an ontology of noise, New York, Bloomsbury, 2013

${ }^{33}$ Hainge's ontological definition of music is as follows:

(i) music is sound that is

(ii) structured,

(iii) eminently expressive since its only form is its expressed content, and hence,

(iv) irreducible to a secondary function (such as representation),

(v) conditioned by an assemblage in the real world (and therefore not transcendent or ahistorical) see Greg Hainge, op. cit., 261. 
White noise is a plane (that does not exist in actuality) of the sum total of all possible sonic frequencies emitted simultaneously. Any sonic expression is then necessarily the contraction into actuality of a zone of this plane or the conjugation of different points of this plane. [...] It is, however, impossible for the content of expression to separate itself from the immanent plane out of which it is formed and the differential process through which it comes to be - 'meaningful' expression becoming such only by contracting noise into a form that no longer seems noisy. ${ }^{34}$

Imagine a person who is not used to listening to noise music or similar genres, but is trained in listening to, and appreciating the values of, traditional European musicality; what would happen if such a person comes across noise music? If this person would like to assume an active attitude towards this genre, they would strive to find at least some sign of musicality in the work. The above attempt at analysis showed - and this is one of its praiseworthy results - that it is, in principle, possible, yet on a limited scale. Using Hainge's terminology, we can say that our hypothetical listener will try to strip the perceived artefact of its noise character (in the common sense definition) and attribute at least some characteristics of musicality to it (they will arguably speak of music, while having in mind what Hainge calls musicality). However, it seems that it is more fruitful to listen to noise music while perceiving its noise nature, rather than try to find 'something like music' in it.

Let us once again return to Hainge's ontology. In his opinion, every sonic expression consists of contracting a part of the infinite virtual plane of noise into the sonorous presence. This ontological process is therefore primary in the expression of all music, but in the case of traditional music, it is completely obscured by secondary encoding into the language of musicality. This encoding then gives such music the illusion of a transcendental order and inner urgency (e.g. based on tonality, formal and tonal principles). By totally ignoring this secondary encoding, Merzbow also rejects the illusion it generates. ${ }^{35}$

Merzbow and the analogue noise music of the 1990s in general were an example of a close relationship between expression, noise, and materiality of the environment in and through which it was played. Sound was created using an array of interconnected effect processors, ones that together generate an unpredictable mass of moving sound layers; the performer sometimes was not in full control of the behaviour of these complex and exact reactions to

\footnotetext{
34 Ibid., 18.

35 Ibid., 262.
} 
manipulating the individual controllers. Yet the performer was the actor who, without a plan prepared beforehand, set the sonic activity in motion, opening a Pandora's box full of noise - only to be flooded with sonic spouts they actuated, then reacted to, time and again. Feedback expanded and ceased to be confined to the effect processor circuits, and absorbed the performer and other participants of the performance. The narrowest possible interconnection of sonic expression with the material nature of the medium in which it takes place, is especially clear in this case. It is not mediated by any secondary encoding, musicality, or representation.

\section{Time, body, symbolic order}

Perceiving noise music as a primary sonic expression without efforts to find a secondary encoding to the music language of European musicality leads to changes in the perception of music time in comparison with traditional music. Deliberately used structural listening in traditional music, as well as subconsciously applied 'proto-analytical' experience of everyday listening to average popular music (also acquired subconsciously through repeated listening to such music), benefits from a double structuring of music time - small-scale (through regular rhythm and metre) and large-scale (through a musical form made by harmony of various components of music). This time structuring has an objective character and the listener has to be able to decode it, at least by intuition. This is not the case with noise music; it has a structure but lacks form as a basis of typical musicality. This means that what has already been played in no way predetermines what is about to be heard. Husserlian retentions sink into the past, and by contrast to traditionally structured music, there is nothing here to bring them back. Noise music is non-teleological music - it contains no partial or final objectives to which any part of the composition would lead.

The method of listening which corresponds to this lack of form anticipates a focus of attention on 'now'. Resignation to the horizontal dimension deepens one's perception of the vertical dimension; the more one narrows one's 'window' of attention to the shortest possible current moment, the clearer one will perceive the number of sonic layers unceasingly pulsating over another in an unpredictable movement, fascinated by a sonic variety one would never expect in the roaring of 'mere' noise. The consequence of concentrating on 'now' is an experience close to Buddhist meditation: it offers the feeling 
of completion and abundance in the present moment to which attention has been fully focused.

A complementary element of listening is the feeling of being 'flooded' with the continuous sonic matter of the track as a whole. Details, as well as the specific course of the composition, lack importance in this mode of perception - what appeals is the overall mass, the incessant flow of moving and varying sound in its totality. It fills us with its intensity relating to the volume, duration, unpredictability, discontinuity, and lack of footing. We find ourselves in the extremely extended 'now'.

These two modes of experience, seemingly contradicting, in fact complement each other. They evoke the Bergsonian term of duration (la durée in French) as a form taken by the sequence of states of consciousness, when the self cannot distinguish past conditions from the present, when the self defies being 'interrupted' by past retentions and their return, persevering in the current 'now'; sometimes this 'now' occupies a short period of time (hundreds of milliseconds to several seconds), other times it is stretched in 'timelessness', filling up to dozens of minutes.

In addition to changes in how we experience time, we can also observe changes to the perception of the stream of music caused by the special nature of noise music. The performer is often absorbed in noise as well as the system through which this noise is produced. Performance then changes into "a transformative personal struggle, in which the performer's intentions are subverted by an out-of-control relationship with an electronic system". ${ }^{36}$

Listeners are exposed to the same flood of sound, the same intensive, primordial energy - but also the absence of any rigid anchors, meaning, representation. Noise is unfathomable, extreme, potentially unpleasant. One listener stated: "You can feel your whole body react when they start - the sound fills your mind completely and you can't think. At first you are just shrinking back, until you overcome that and let it go, and then you're in it and you're just being blown away". ${ }^{37}$ "Noise music addresses me as matter", said Marie Thompson and then described the physical experience:

[...] the sound expanded, filling the spectrum, creating a wall of noise. My whole body began to vibrate; my attention was turned inside, to my lungs, my stomach. The sound was, quite literally, force [...] bringing to the fore my existence as vi-

\footnotetext{
${ }^{36}$ David Novak, Japanoise: music at the edge of circulation, Durham, Duke University Press, 2013, 156.

37 Ibid., 46.
} 
brating, affective matter. [...] It transforms the organs into a thousand ears, the ears into a vibrating, fluttering drum skin. [...] I can feel it in my lungs, my stomach, my throat; it can turn me inside out. ${ }^{38}$

These reactions describe the physical feeling of one's body materiality on the one hand, and a combination of feelings of threat and intoxication on the other. This combination is suggestive of the term jouissance, which, in Lacanian psychology, denotes the power which forces a person to cross the borders of pleasure already attained. This suggests crossing the symbolic order, being the basis of language, meaning - and, as a consequence, also of culture, order, and law. This forms humankind, while standing outside the Self as the Other. Forming means limitation, but transgressing it turns pleasure into suffering.

How noise music relates to these Lacanian terms, is explained by Csaba Toth: Noise

[...] disrupts both the performer and listener's normal relations to the symbolic order by refusing to route musical pleasure through the symbolic order [....]. We can call this musical pleasure [...] jouissance, achieved by self-negation, by a return to the imaginary or the pre-subjective (the stage that precedes ego differentiation) - which, in our context, is a sonorous space. ${ }^{39}$

In a similar vein, Simon Reynolds wrote: noise is “... the antithesis of meaning. If music is a language, [...] then noise is like an eruption within the material out of which language is shaped. We are arrested, fascinated, by a convulsion of sound to which we are unable to assign a meaning." 40

While traditional music may be regarded as part of the symbolic order and, due to structural and social reasons, as a representation of power relations in society and their reflection in human thinking, ${ }^{41}$ noise music as a passing process lacking form is a destructive opposition to the influence

\footnotetext{
38 Marie Thompson, "Music for cyborgs: the affect and ethics of noise music", in: Michael Goddard, Benjamin Halligan, and Paul Hegarty (Eds.), Reverberations: the philosophy, aesthetics and politics of noise, London, Continuum, 2012, 213.

39 Csaba Tóth, "Noise Theory", in: Anthony Iles and Mattin (Eds.), Noise \& capitalism, San Sebastián, Arteleku, 2009, 28.

40 Simon Reynolds, "Noise", in: Christoph Cox and Daniel Warner, Audio culture: readings in modern music, New York, Continuum, 2004, 57.

41 See Attali's description of the representation phase (Jacques Attali, Noise: the political economy of music, trans. B. Massumi, Minneapolis, University of Minnesota Press, 1985, $46+)$.
} 
of the symbolic order. The resulting effect may not be subversive, but rather self-subversive, leading, as Simon Reynolds wrote, to at least temporary "overthrowing [of] the power structure in your own head". 42

\section{Conclusion}

As Greg Hainge's ontological analysis has shown, it is instrumental to separate the term music in the general sense from the meaning as defined by relational ontology. In the first case, music is defined by fundamentally arbitrary rules, historically, locally, or otherwise subjectively conditioned, termed as musicality by Hainge. In the other case, Hainge asserts that music is any sonic expression that fits his simple, general criteria. In this sense, even fringe sonic expressions like the japanoise examined in this study may be regarded as music. Since these expressions lack characteristics included in Hainge's term of musicality, it is not possible to address them using the methods based on these characteristics. It is necessary to search for other ways to interpret this musical genre. This is all the more important as new types of sonic expressions are unceasingly emerging, which have little to do with the layman's conception of music (for instance, glitch and noise music, live coding, sonification, the whole domain of sonic expressions based on field recordings, soundscape, soundwalk, etc.). These kinds of 'music' may also have extra-musical functions, but they can also be viewed as aesthetic objects sui generis. The number of such extreme music genres are expected to increase, and they will gradually lose their extreme status.

Thus, musicology finds itself in a new situation - or, more exactly, in a situation which is and will be new, over and over, ever-changing. And, it has to adequately react to this situation.

\section{Attachment}

For the purpose of comparison, we present spectrograms of four musical pieces of different genres where the spectral character is very diverse. These are:

Merzbow: Wing Over (noise music - the piece which was analysed in the paper)

Dennis Smalley: Wind Chimes (electroacoustic music)

42 Simon Reynolds, op. cit., 57. 
Meshuggah: Bleed (trash metal / progressive metal)

W.A.Mozart: Symphony No. 29, first movement (classicism)

For the purpose of easy comparison, all spectrograms display roughly the same length of the audio sample (just over two minutes). The value of time lies on the horizontal axis, the frequency lies on the vertical one; the value of intensity at each point is represented by colour from black (the lowest) through green, yellow to red (the highest). The sequence of red spots shows the spectral centroid at every moment of the composition.

The pictures present considerable differences in spectral characteristics of individual compositions. Wing Over is characterized by a complexly filled spectrum without visible regularity, with only exceptionally discernible sound objects (12:30, around 13:25, 13:55), and a very high spectral centroid. In Wind Chimes, on the other hand, we see a lot of silence and quite clear 'pieces' of sound, quite clearly bounded in both horizontal and vertical directions. Although the individual (not shown here) segments of this song look different, these basic characteristics remains the same all the time. Bleed is characterized by high regularity, which is disturbed only by the yellow wavy lines stretching roughly in the middle of the picture (about $1 \mathrm{kHz}$ ), depicting the singer's expression. Otherwise, the spectral characteristics do not change over the whole composition, each instrument has its fixed place. In Mozart's Symphony 29, we see both the lowest spectral centroid and, above all, the clear lines of higher harmonic tones culminating in the vertical direction. This results from the fact that classical music contains far less noise than other audio examples. 
Kubiček, J.: From Kerman to Merzbow: Notes on the Metamorphoses of Music Analysis...

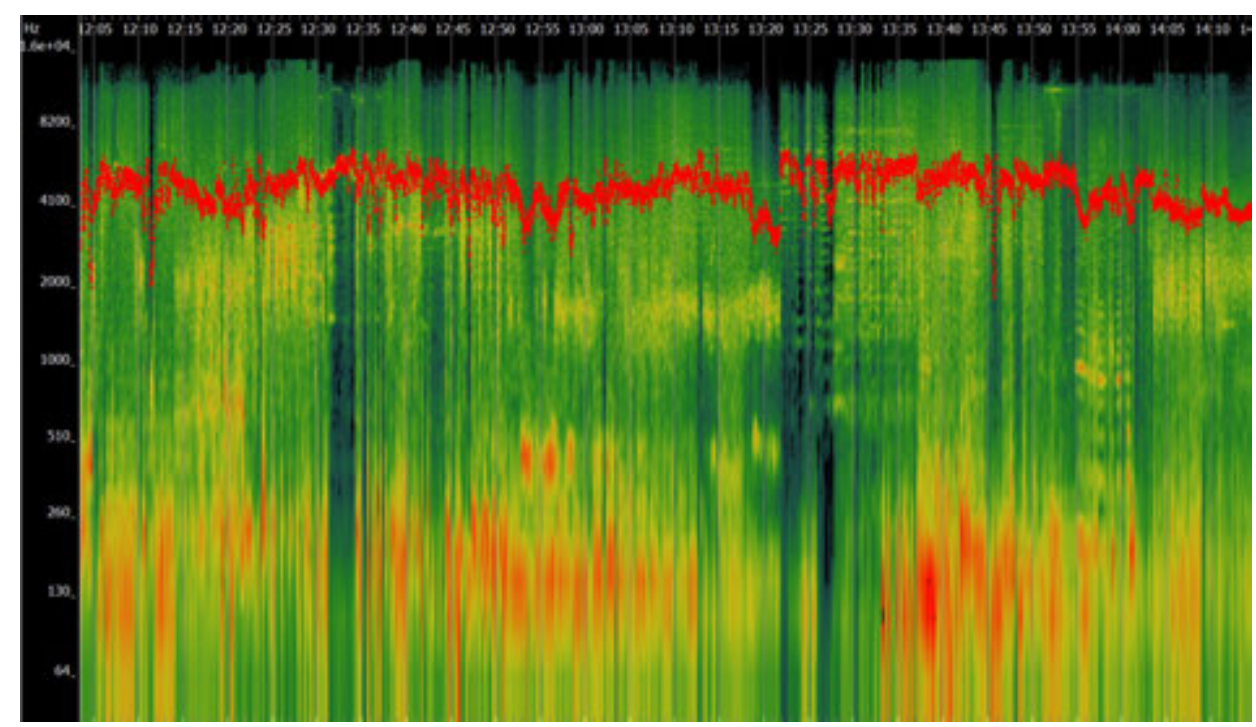

Figure 1: Merzbow - Wing Over

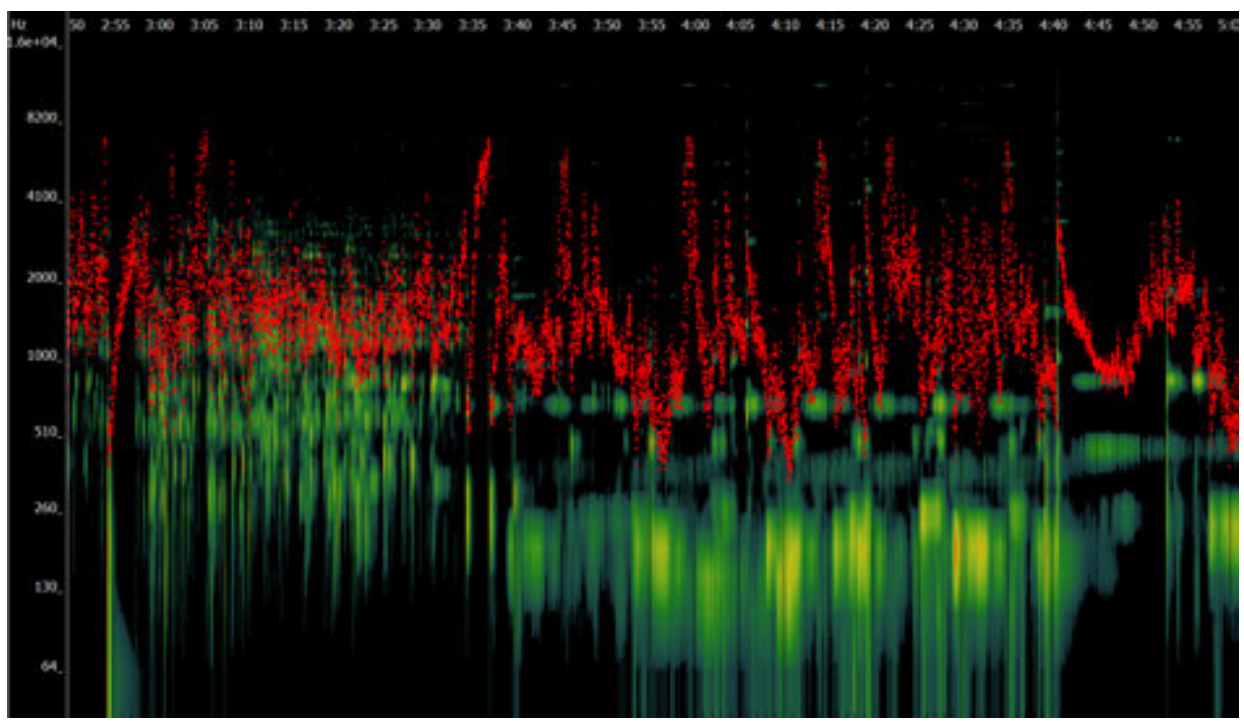

Figure 2: Dennis Smalley - Wind Chimes 


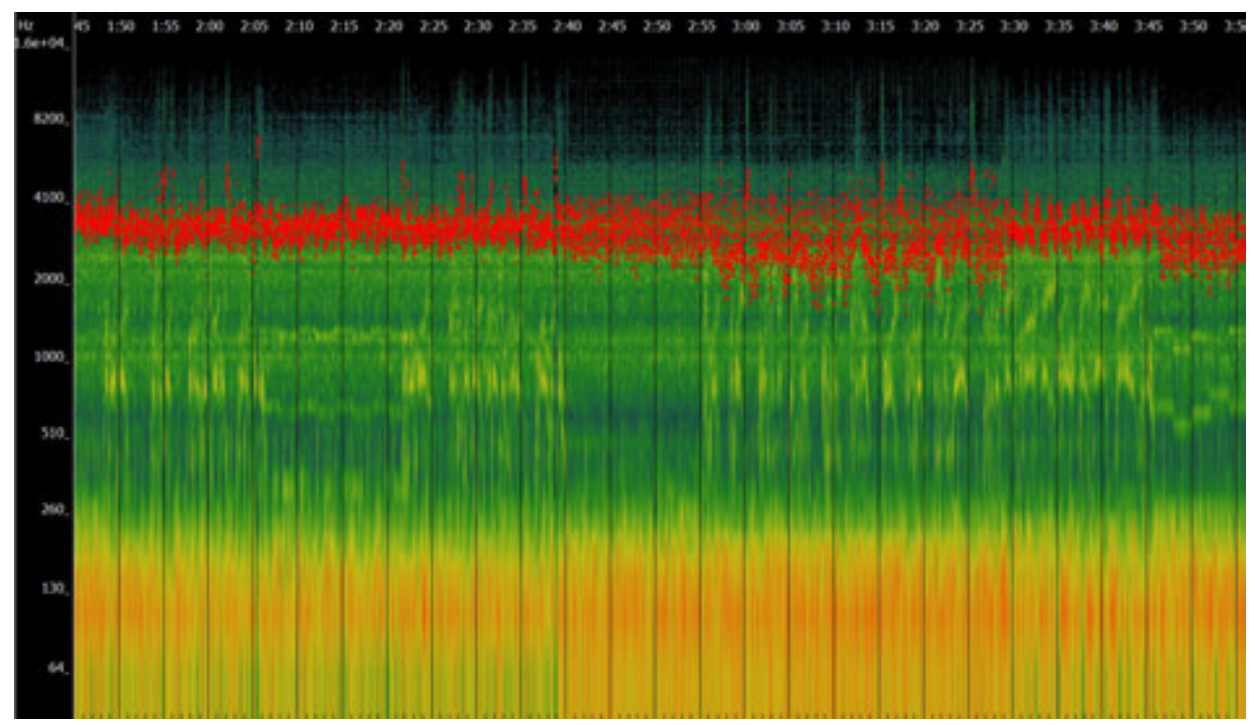

Figure 3: Meshuggah - Bleed

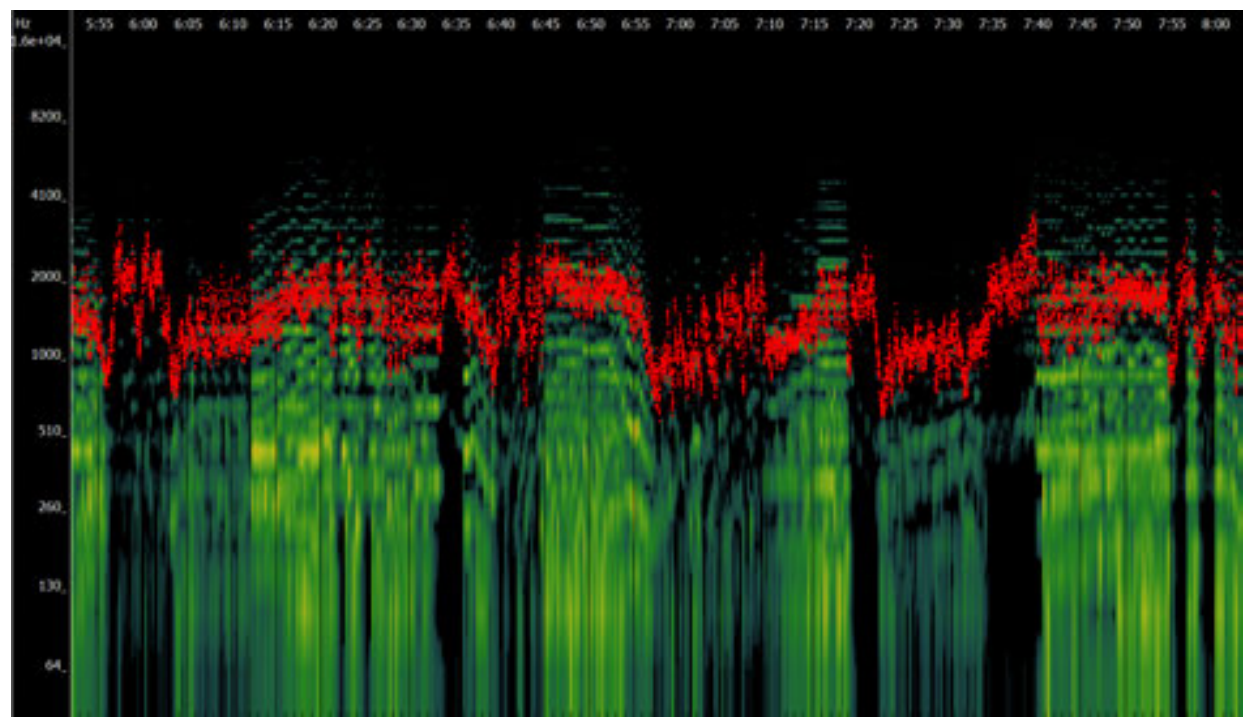

Figure 4 : W.A.Mozart - Symphony No. 29, first movement

Furthermore, there is a detailed picture of Wing Over, the part which was analysed. 


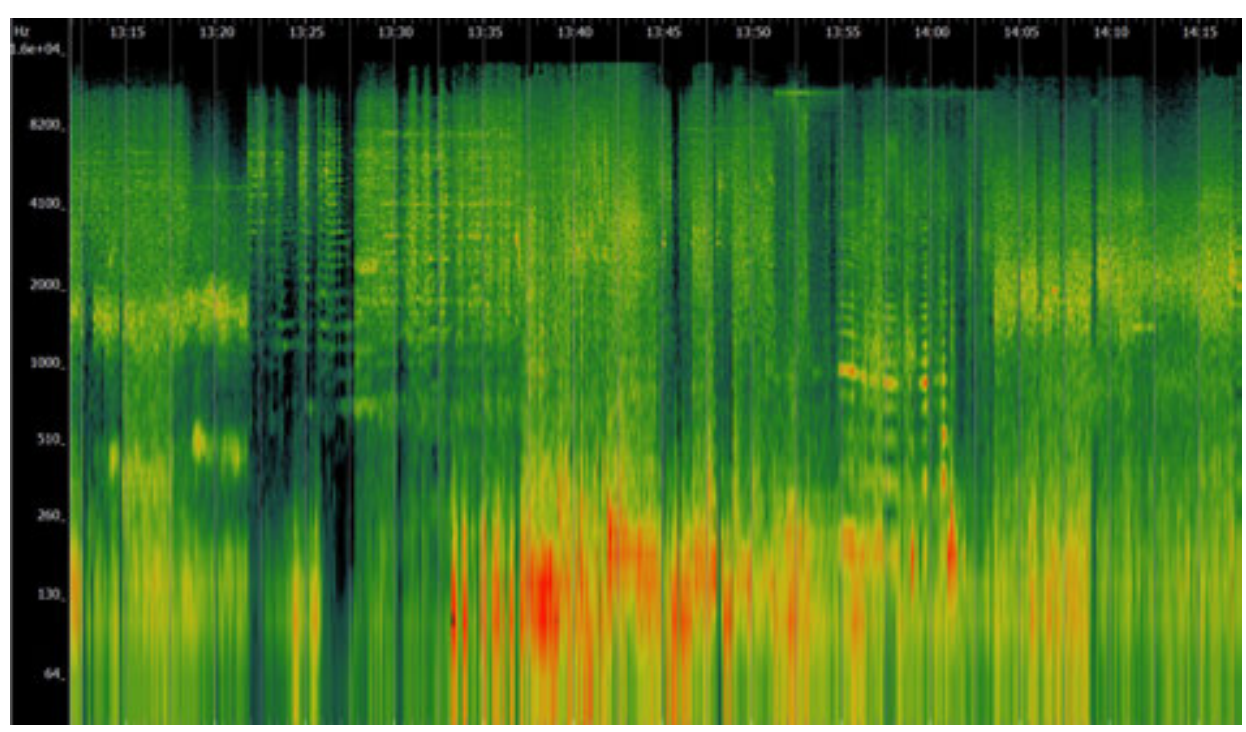

Figure 5: Merzbow - Wing Over, 13:13 - 14:15.

All spectrograms were created using Sonic Visualiser software, developed at Queen Mary, University of London.

\section{Acknowledgement}

The study was supported by the Czech Ministry of Education, Youth and Sports, project IGA_FF_2017_038 (Theory, History and Editing of Music from the 19th to the 21st Century).

\section{Works Cited}

Agawu, Kofi: "How We Got out of Analysis, and How to Get Back in Again", Music Analysis, 23, 2004, 267-286.

Andean, James: "Narrative Modes in Acousmatic Music", Organised Sound, 21, 2016, 192203.

Attali, Jacques: Noise: the political economy of music, transl. B. Massumi. Minneapolis: University of Minnesota Press, 1985.

Clarke, Michael: "Analysing Electroacoustic Music: An Interactive Aural Approach", Music Analysis, 31, 2012, 347-380.

Cook, Nicholas: A Guide to Musical Analysis. Oxford - New York: Oxford University Press, 1987. 
Cook, Nicholas, Mark Everist: Rethinking Music. Oxford: Oxford University Press, 2010. Eco, Umberto: The Limits of Interpretation. Bloomington: Indiana University Press, 1994. Gatt, Michael E.: Tools for Understanding Electroacoustic Music. Thesis submitted for the degree of Doctor of Philosophy. Leicester: De Montfort University, 2014.

Hainge, Greg: Noise matters: towards an ontology of noise. New York: Bloomsbury, 2013.

Kerman, Joseph: "How We Got into Analysis, and How to Get Out", Critical Inquiry, 7, 1980, 311-331.

Kramer, Jonathan D.: "The Concept of Disunity and Musical Analysis", Music Analysis, 23, 2004, 361-372.

Landy, Leigh: Understanding the art of sound organization. Cambridge, Mass.: MIT Press, 2007.

Morgan, Robert P. : “The Concept of Unity and Musical Analysis”, Music Analysis, 22, 2003, 7-50.

Novak, David: Japanoise: music at the edge of circulation. Durham: Duke University Press, 2013.

Reynolds, Simon: "Noise", in: Christoph Cox and Daniel Warner, Audio culture: readings in modern music. New York: Continuum, 2004, 55-58.

Schaeffer, Pierre: Treatise on musical objects: essays across disciplines, transl. Ch. North and J. Dack. Oakland: University of California Press, 2017.

Smalley, Denis: "Spectromorphology: Explaining sound-shapes", Organised Sound, 2, 1997, 101-126.

Stockhausen, Karlheinz: "Momentform: Neue Beziehungen zwischen Aufführungsdauer, Werkdauer und Moment", in: Dieter Schnebel (Ed.), Texte zur Musik, Vol. 1. Cologne: DuMont Schauberg, 1963, 189-210).

Thompson, Marie: "Music for cyborgs: the affect and ethics of noise music", in: Michael Goddard, Benjamin Halligan, and Paul Hegarty (Eds.), Reverberations: the philosophy, aesthetics and politics of noise. London: Continuum, 2012, 207-218.

Tóth, Csaba: "Noise Theory", in: Anthony Iles and Mattin (Eds.), Noise \& capitalism. San Sebastián: Arteleku, 2009, 24-37.

Wallmark, Zachary T.: Appraising Timbre: Embodiment and Affect at the Threshold of Music and Noise. A dissertation submitted in partial satisfaction of the requirements for the degree Doctor of Philosophy in Musicology. Los Angeles: University of California, 2014. 